\title{
Origin of the International Potato Center
}

The International Potato Center [Centro Internacional de la Papa (CIP)] was established in 1971 through an official decree issued by the government of Peru. The mandate of this center, as set forth in that decree, is to undertake research for the improvement of the potato and other tuber and root crops, both nationally and internationally, to contribute to the availability of food in the developing world. This broad mandate also calls for the collection, maintenance, and distribution of germplasm; help in the development of national research capabilities, both in Peru and elsewhere; training of scientists in developing countries; and diffusion of information related to potato improvement.

Peru was the ideal location for a center dedicated to research on the potato (Solanum tuberosum). In the Andes, the home of the potato, there is easy access to numerous wild and primitive species of Solarium that can serve as valuable breeding material. The incidence of the major pests and diseases affecting a crop is also greater in its area of origin. And, finally, Peru's agroclimatic diversity (back cover, top) provides a distinct advantage in that experimentation at CIP'S stations throughout the country can be conducted under climatic conditions that represent those of the majority of developing countries.

In 1972, CIP became part of the newly formed Consultative Group for International Agricultural Research (CGIAR), a consor-

Received for publication 11 Nov. 1990. The cost of publishing this paper was defrayed in part by the payment of page charges. Under postal regulations, this paper therefore must be hereby marked advertisement solely to indicate this fact.

Front cover: Upper left. The headquarters of the International Potato Center is located in Lima, Peru. At these research facilities, CIP scientists work on various problems of potato and sweetpotato production in developing countries. Upper right. Potato plants at full bloom growing under the favorable environmental conditions present in Osorno, Chile (lat. $41^{\circ}$ south). Center left. Sexual seed of potato as an alternative to seed tubers. Center right. Marketable-size potato yields averaging $\approx 1 \mathrm{~kg}$ per plant (hill) were produced with transplants of high quality true seed. Lower left. Peruvian worker digging small trench with native women watching. The true potato seed technology is proving to be a feasible alternative for increasing potato production in developing countries. Lower right. Large-scale seed production in southern Chile is conducted by pollinating nonemasculated flowers before anther opening to reduce selfing contaminations. tium of more than 45 countries, international and regional organizations, and private foundations. CGIAR was established in 1971 under the joint auspices of the International Bank for Reconstruction and Development (World Bank), the United Nations Development Program (UNDP), and the United Nations Food and Agriculture Organization (FAO). It currently includes 13 international agricultural research centers. The aim of CGIAR is to pool efforts aimed at improving the quantity and quality of food production in the developing world.

In 1985, CIP's research program was broadened to include sweetpotato. In making this decision, several important factors were taken into account: 1) CIP's location in the area of origin of the sweetpotato; 2) the research complementarily of potato and sweetpotato; 3) CIP's global distribution system, already in operation; and 4) the fact that sweetpotato deserved a more concentrated research effort than it had received up to that time.

\section{Fulfilling the center's mission}

CIP's mission has been summarized as follows:

"To help developing countries increase food production, develop sustainable agricultural systems, and improve human welfare through potato and sweetpotato research and development. CIP's collaborative research and training is designed to enhance the capacity of developing country scientists to determine and utilize the unique potential of each commodity within the local food systems. By stimulating collaboration among countries, CIP hopes to promote mutual comprehension and interdependence in solving common problems. Thus, while contributing directly to agricultural production, this center can help scientists across the developing world to respond flexibly and successfully to changing demands in agriculture, and by doing so increase their contribution to society and their personal sense of productivity."

Several basic operational tactics have been developed at CIP and applied over the years to help in meeting the center's mission. Among them are the following:

CIP has a widespread Regional Program (back cover, center), with eight headquarters located throughout the developing world. The stationing of scientists in the regions allows for direct and continuing contact with the ag- ricultural research programs in the area, and for on-site testing and adaptation of technologies. It also provides valuable feedback that is used to determine and orient research priorities, as well as bases for training activities. Senior scientists stationed in the regions maintain close and continuing contact with the scientists and farmers in the area as they assess and service localized needs.

CIP has also promoted the development of five Country Networks (back cover, bottom), cooperative research systems comprising several countries in a geographical region. Through these networks, countries that do not have the resources or the priority for assuming a comprehensive program for research with potatoes are able to pool their resources, each assuming responsibility for one or several projects focused on common problems - according to the members' comparative research advantages - and then sharing the results with the others. This approach also contributes to growth in self-reliance within the national scientific communities.

To broaden its research base, CIP invests annually in close to 60 Collaborative Research Contracts. The contract approach to research allows this center to take advantage of expertise and facilities existing elsewhere, thus opening up possibilities in subjects that CIP does not have the capacity to cover directly within its own research program. In disciplines such as biotechnology, for example, CIP is able to be involved in the mainstream of innovative scientific developments with a much lower investment than if the research were to be conducted exclusively at the center. Another advantage of contract research is that through these collaborative efforts, long-term formal and informal associations are developed, providing channels for a two-way flow of information as well as important opportunities for input and exchange of information.

\section{The tropical potato}

Through these collaborative bridges, CIP works toward the improvement of food supplies for the peoples of the developing countries. As the majority of these countries are located in the tropics, CIP's efforts are largely concentrated on the particular problems and concerns of tropical areas. In the case of potato, this involves the adaptation of a crop traditionally considered to be suited only for temperate highland areas to the growing conditions of the warmer lowlands. This concern is not, however, one that has been created by CIP and then promoted in tropical areas; rather, it is an attempt to respond to already existing demands in these areas, and to expand upon the known potential of the potato crop.

\section{The promise of true potato seed}

In tropical areas, a major constraint to potato production is the high cost and scarcity

(continued on inside back cover) 
(continued from inside front cover)

of high-quality planting materials. Innovative alternative methods of vegetative potato propagation, such as the use of rapid multiplication with cuttings, have been developed by CIP to aid national potato seed programs. A significant amount of research is dedicated to the development of a true potato seed (TPS) as an alternative to planting with tubers. TPS represents an ideal example of a novel, sustainable technology suited to tropical areas where the use of low-quality seed tubers results in potato production for luxury consumption only. In addition to TPS having much lower costs of production, storage, and transportation than seed tubers, few potato diseases are transmitted by TPS.

At CIP, TPS progenies have been selected that produce stable high yields of uniform tubers in short-day environments. On-farm research on the uses of TPS is being carried out in more than 40 developing countries, and more potatoes are being produced from TPS commercially. Large quantities of highquality TPS are produced by CIP in southern Chile, in collaboration with the national potato research program and seed growers. This TPS is provided by CIP free of charge upon request for research purposes. Methods for efficient production of TPS are being transferred to key areas in the developing world where the demand for TPS is growing. CIP has also been successful in stimulating private concerns to supply the ever-growing demand for commercial use of TPS.

The challenge to develop TPS technology to its limits was taken up by CIP scientists about a decade ago. Much progress has been made, but much more is still needed before TPS can claim to be another "green revolution". Resistance to tropical diseases needs to be incorporated into TPS progenies. The factors that limit market potato production using TPS transplants or direct-seeding TPS are physiological problems in need of solutions. Vigorous crop establishment, early maturity, more-uniform yields with acceptable tuber size and shape are the constant objectives of CIP scientists working on TPS.

CIP will likely continue to spearhead this truly innovative alternative method of propagating potatoes in developing countries throughout this century. collaborative research projects using the comparative advantages of CIP scientists and those in the public institutions of developed nations interested in participating in the TPS challenge are welcome and will accelerate the rate of 'ITS technology development.

\section{The challenge for the future}

CIP'S challenge within the global needs for agriculture for the next 20 years contemplates several factors that are gaining in importance daily, and that must be considered if the world population is to be properly and equitably fed in coming years. They include the rapidly increasing rates of growth in population, the scarcity of good land, and the concern for environment. More food must be produced on the already available land in a way that will not deteriorate our valuable natural resources. Among other things, this will call for a balancing of extensively produced crops, such as the cereals, with the more intensively produced vegetables and tuber-root crops.

Within this framework, CIP aims to contribute to the availability of important sources of nutrition by helping to fit potatoes and sweetpotatoes into the diverse farming systems of the world, and, in doing so, to increase the productivity of quality food per unit area per unit of time, increase the efficiency of use of inputs such as fertilizer and water, and sustain the increases in productivity in a way that is friendly to the environment.

N. Pallais

International Potato Center

Apartado 5969

Lima, Peru 